\title{
A gestação do golpe no Uruguai: o governo Bordaberry e o papel dos militares (1972-1973)
}

\author{
The gestation of the coup in Uruguay: Bordaberry \\ administration and the military's role (1972-1973)
}

\author{
Enrique Serra Padrós* \\ Ananda Simões Fernandes**
}

Resumo: A conjuntura política uruguaia entrou em franco processo de deterioração a partir de 1968 e se acelerou no biênio 1972-1973. A falta de respostas do governo Bordaberry para atender as demandas a tanto tempo reprimidas associou-se à insistência de uma política econômica que inviabilizou qualquer expectativa de mudança de rumo em curto prazo, à ascensão das Forças Armadas e às dramáticas opções políticas realizadas. Estes fatores acabaram resultando no golpe de Estado no Uruguai, em 27 de junho de 1973.

Palavras-chave: Uruguai, Governo Bordaberry, Golpe de Estado

\begin{abstract}
The Uruguayan political situation got into a deep process of deterioration since 1968 and it increased in the biennium 1972-1973. The lack of answers from the Bordaberry administration to solve old repressed demands was associated to its insistent economic policy which prevented any expectative of short-term changes. It was also linked to the rise of the Armed Forces and to dramatic political options performed by his government. These elements resulted in the Uruguayan Coup d'etat in June, $27^{\text {th }}, 1973$.
\end{abstract}

Keywords: Uruguay, Bordaberry administration, Coup d'état

* Professor do Departamento e do Programa de Pós-Graduação em História da Universidade Federal do Rio Grande do Sul. Doutor em História/UFRGS. E-mail: < lola@adufrgs.ufrgs.br >.

** Técnica em Assuntos Culturais do Arquivo Histórico do Rio Grande do Sul. Mestre em História/UFRGS. E-mail: <ananda-fernandes@sedac.rs.gov.br>. 


\section{Antecedentes}

Com a chegada à presidência de Jorge Pacheco Areco, em dezembro de 1967, iniciou-se um crescente autoritarismo no Uruguai, com a utilização constante de medidas de exceção, técnicas repressivas e violência política. Durante o período da escalada autoritária neste país - que se estende até o golpe de Estado, em 1973 -, começaram a se manifestar os elementos que posteriormente seriam utilizados pela ditadura, e que a caracterizam como um regime baseado na promoção do Terrorismo de Estado. Isso faz com que o período autoritário que se iniciou com Pacheco Areco e continuou durante o governo do presidente golpista, Juan María Bordaberry, seja denominado como o do "golpe de Estado mais longo", "golpe em câmara lenta", "governo semi-ditatorial" ou, ainda, de "ditadura constitucional" (JELLINEK; LEDESMA, 1980).

Quanto à administração Pacheco Areco as primeiras medidas foram a dissolução de partidos políticos e organizações vinculados à esquerda, tais como o Partido Socialista, a Federación Anarquista Uruguaya, o Movimiento Revolucionario Oriental, o Movimiento de Acción Popular Uruguaya e o Movimiento de Izquierda Revolucionario, e o fechamento dos periódicos Época e El Sol, acusados de serem subversivos. O uso do poder discricionário contra os setores populares, os trabalhadores e os estudantes foi a principal ação política do governo. O presidente, a fim de conter o processo inflacionário no Uruguai, começou a seguir cada vez mais as diretrizes impostas pelo Fundo Monetário Internacional (o país estava filiado ao FMI desde 1949). Para tanto, era necessário restringir os direitos dos trabalhadores e seus benefícios salariais, situação essa rejeitada pela população. Os trabalhadores uruguaios já haviam alcançado um alto nível de consciência de classe, e não estavam dispostos a permitir a perda de seus direitos. O uso generalizado e intensivo de medidas de exceção (as Medidas Prontas de Seguridad), que restringiam as liberdades individuais durante, no máximo, 30 dias, foi um dos traços mais marcantes dessa administração; com seu uso constante e ilegal, começou intensa criminalização das manifestações pacíficas de contestação ao regime. Previstas na constituição uruguaia, tais medidas de exceção já haviam sido utilizadas durante a administração anterior. Entretanto, foi neste governo que houve a banalização do seu uso.

Assim, a administração Pacheco Areco propiciou, paulatinamente, a implantação de medidas que seriam ampliadas e consolidadas durante a ditadura civil-militar que iniciou em 1973 e se estendeu até o início de 
1985. Desse modo, práticas extremadas de violação dos direitos humanos, como o uso intensivo de medidas de exceção, aplicação da tortura, formação de Esquadrões da Morte, censura e repressão aos movimentos sindical e estudantil, foram empregadas durante o Pachecato. De certa forma, esse governo foi um ensaio do que se constituiria futuramente, a partir da implantação da ditadura de segurança nacional.

$\mathrm{O}$ autoritarismo exercido por tais governos antecipou um regime de medo e de terror, na medida em que foi durante este período que houve a gestação dos elementos do Terrorismo de Estado, acabando por sistematizar e transformar em política de Estado a sua utilização, a partir do golpe de 1973. Assim, os elementos que depois seriam utilizados pelo Estado ditatorial - tortura, censura, sequestros, desaparecimentos, repressão aos trabalhadores e aos estudantes - se encontravam presentes, paradoxalmente, durante o período democrático. Quando a política do Terrorismo de Estado foi acionada no Uruguai, o regime de exceção já possuía o aparato repressivo necessário, tanto por causa da sua experiência interna, quanto pela cooperação recebida dos Estados Unidos e da ditadura brasileira.

A utilização de medidas que, paulatinamente, configurariam o Uruguai como um Estado que recorria ao autoritarismo para impor suas decisões e a necessidade do golpe de Estado foram justificadas pela atuação das organizações de luta armada, destacadamente o Movimento de Libertação Nacional (MLN), mais conhecido como tupamaros. Entretanto, essas duas afirmações precisam ser relativizadas. A escalada autoritária ocorreu como resposta às mobilizações sociais, decorrentes da recessão econômica e do quadro de deterioração que o Uruguai atravessava desde o final dos anos 1950. O Estado conseguia conter essas manifestações somente por meio do uso da violência, mecanismo também utilizado por grupos violentos de extrema-direita que agiam sob a sombra da omissão estatal diante dos seus crimes e, portanto, da impunidade (BUCHELI, 2008). Desse modo, o surgimento e consolidação dos tupamaros resultaram de um autoritarismo latente, não sendo produtor deste. A guerrilha também foi utilizada como justificativa preventiva para explicar o golpe de Estado. Porém, esta modalidade de luta já havia sido desestruturada um ano antes. Eram a formação da Frente Ampla, o seu crescimento político-eleitoral e a eleição de uma importante base parlamentar, assim como a forte presença dos movimentos sociais, que preocupavam os setores conservadores e as Forças Armadas. O golpe de 27 de junho foi, principalmente, contra essas organizações; entretanto, de forma não usual entre as ditaduras 
do Cone Sul, foi o próprio presidente democraticamente eleito quem chamou os militares para compor o seu governo.

\section{A administração Bordaberry: da eleição ao golpe de Estado}

Juan María Bordaberry foi a alternativa eleitoral oficialista diante da impossibilidade de reeleição de Pacheco Areco. Em eleições apertadas e com acusações de fraude, Bordaberry deu sequência e aprofundou a espiral autoritária em gestação. Seu primeiro grande desafio foi construir uma base mínima de sustentação parlamentar, já que seu setor político contava somente com sete senadores de 30 e 28 deputados de 99 . Num primeiro momento, garantiu a manutenção da aliança constituída na gestão anterior em troca de cargos e da inclusão de pontos programáticos daquelas correntes no programa de governo; assim, Bordaberry atraiu os setores do líder colorado Jorge Batlle, bem como a minoria blanca conservadora - o que lhe garantia, em hipótese, o apoio de 16 senadores (sobre um total de 30) e de 50 deputados (sobre 99). Sua grande derrota foi não obter apoio de Wilson Ferreira Aldunate nem dividir sua base parlamentar. Considerando a coesão da esquerda e o virtual equilíbrio político entre governo e oposição (nas situações conjunturais em que esquerda e blancos de Ferreira Aldunate coincidiam, representavam quase $40 \%$ de votos contra o governo), produzia-se a seguinte lógica de confronto: o governo evitava o Parlamento e assumia a estratégia de esvaziamento das suas sessões enquanto que a oposição tentava acuar os ministros de Bordaberry (NAHUM, 1995, p. 281). Porém, alguns setores da maioria blanca distanciavam-se dos grupos radicais da Frente Ampla e faziam forte crítica ao MLN, assumindo postura diferente daquela da coalizão de esquerda, que tinha uma posição ambígua em relação à organização guerrilheira.

De qualquer forma, essa paridade inicial de forças no Parlamento significou um retorno sui generis do regime democrático, já que as Medidas Prontas de Seguridad foram momentaneamente deixadas de lado, o movimento sindical se reativou (organizando 13 greves gerais em seis meses) e a elite política retomou a totalidade dos cargos no gabinete em detrimento do perfil tecnocrata-empresarial e desconectado dos partidos tradicionais da gestão anterior (VARELA, 1988, p. 126). Mas, rapidamente, a situação se deteriorou, retomando-se a espiral de violência de esquerda e de direita enquanto reforçava-se a impotência do Parlamento para frear os avanços do autoritarismo e o desmoronamento das normas de convivência democrática. 
O governo Bordaberry, como fizera o de Pacheco Areco, priorizou a luta antissubversiva. Três foram os motivos principais. Primeiro, porque o MLN havia crescido em quadros ativos, em nível operativo, em armamento e em base política, desafiando não só o governo, mas os partidos tradicionais como um todo; estes reconheciam que havia limites constitucionais que exigiam a eliminação da guerrilha. Segundo, a luta contra a "subversão" era a única iniciativa em que o governo podia contar com o apoio de Ferreira Aldunate (o que não significava coincidência nos instrumentos e métodos repressivos utilizados), isolando a esquerda. Terceiro, abria espaço para a irrupção protagônica das Forças Armadas, o que mudaria a relação no quadro de forças em benefício do governo (VARELA, 1988, p. 127). Consequentemente, o confronto com o MLN se intensificou; após a trégua eleitoral de 1971, a organização guerrilheira retomou as ações armadas, o que serviu de pretexto para o recrudescimento repressivo.

A guerrilha concluía que, sem intensificar o confronto com o governo, tornava-se impossível atrair os setores populares ainda distantes do MLN. Enquanto isso, a aplicação da tortura pelas forças repressivas e uma intensa pugna entre o Poder Executivo e os demais poderes tornaram-se rotina. O governo respondia com a lógica "ordem versus subversão", identificando como "inimigo interno" a todo cidadão que assumisse posicionamento crítico contra ele. Desta forma, o estado uruguaio procurava, perigosamente, alijar a esquerda parlamentar da dinâmica política. Em fevereiro de 1972, dentre outras ações, o MLN sequestrou um integrante do "Esquadrão da Morte" (o fotógrafo e funcionário policial Nelson Bardesio). A partir do depoimento deste, o MLN forneceu informações sobre aquela organização a juízes, fiscais e legisladores e divulgou que:

Hemos demostrado del modo más palmario que el Escuadrón de la Muerte no se mueve en las sombras, ni mucho menos, se mueve desde el Ministerio del Interior, desde el Comando de las Fuerzas Conjuntas, desde el Gobierno. Tiene nombres y apellidos notorios; viste (o mejor, ensucia) el uniforme de las Fuerzas Armadas (MLNTupamaros, 1972).

Neste documento producido pelos tupamaros, registravam os nomes daqueles que foram condenados à morte pelo Tribunal del Pueblo. No mês de abril, ocorreu o início do desfecho. Após a fuga de 15 prisioneiros do presídio de Punta Carretas (12/04), o MLN desencadeou a ofensiva do dia 14 de abril, orientada pela avaliação de que havia necessidade 
de intensificar o confronto para ter maior incidência sobre a população. As consequências de tal decisão, entretanto, foram completamente inversas ao que era esperado. Na manhã daquele dia, os tupamaros executaram o vice-secretário do Interior, Armando Acosta y Lara, e mais três integrantes das forças repressivas, todos acusados de vinculação com o Esquadrão (fato confirmado pelas declarações de Bardesio).

A resposta repressiva veio no mesmo dia, numa escalada inédita. Diversos esconderijos da guerrilha, mapeados anteriormente, foram atacados; oito tupamaros foram mortos. As ações das Forças Armadas e dos grupos paramilitares não se restringiram ao MLN; outros setores da esquerda também foram atingidos. Entre os dias 15 e 16 de abril, dezenas de atentados perpetrados por forças paramilitares atingiram residências de diversos advogados e figuras públicas identificadas com a Frente Ampla, assim como alguns dos seus comitês de bairros, uma imprensa, a Igreja Metodista (local onde o comando tupamaro disparara contra Acosta y Lara) e a residência do editor de Marcha, Carlos Quijano (MARTÍNEZ, 2002, p. 39). A estratégia do MLN desconhecia que desde o final do ano anterior as Forças Armadas haviam recebido a incumbência de se preparar para assumir a luta contra a guerrilha. Durante meses, enquanto aguardavam um momento propício, os militares se prepararam através de ações de infiltração e inteligência. Quando o MLN desencadeou a ação ofensiva do dia 12 de abril foi pego de surpresa pela contundência e eficiência da resposta militar.

Diante da onda de violência, a Assembleia Geral aprovou, no dia 15 de abril, a suspensão das garantias individuais, de acordo com os artigos 253 e 31 da Constituição, ${ }^{1}$ declarando o Estado de Guerra Interno (por 30 dias) e legitimando a repressão desencadeada contra toda oposição à administração. O governo pressionava pela aprovação dessa lei desde o dia 6 de abril. O espírito da mesma era o de criar mecanismos para enfrentar situações de conflito não contempladas pela Constituição. Em realidade, com a aprovação do Estado de Guerra Interno, o Parlamento legalizou o que já acontecia de fato, ou seja, ações policiais sem necessidade de ordem judicial, interrogatórios sem prazo, suspensão de habeas corpus, a intervenção da Justiça Militar nos delitos políticos, a criação de novos delitos, o aumento das penas e a reclusão dos detidos em qualquer parte do país (MARTÍNEZ, 2002, p. 21).

1 O artigo 31 estabelecia que a segurança individual somente poderia ser suspensa com a anuência da Assembleia Geral. O artigo 253 garantia a jurisdição militar sobre delitos militares e no caso do Estado de guerra. 
Logo em seguida (17/04), ocorreu o massacre contra uma sede do Partido Comunista Uruguaio (Seccional 20). Oito trabalhadores, militantes do partido, foram assassinados e considerados, pelas Forças Armadas, "subversivos" mortos em enfrentamento. Nesse acontecimento, morreu um oficial do Exército, atingido pelo "fogo amigo", mas a responsabilidade dessa morte foi imposta aos trabalhadores comunistas executados. Tudo indica que no ataque participaram homens do Esquadrão, o que poderia desresponsabilizar as Forças Armadas de uma ação cometida por organizações paramilitares. Porém, as Forças Armadas deram cobertura aos responsáveis pelo massacre, protegendo-os, obstaculizando toda informação a respeito e ameaçando testemunhas.

O MLN respondeu com mais violência no dia do Exército (18/05), abatendo cinco soldados que faziam a guarda do Comandante-emChefe. O contra-ataque foi devastador. Em poucos meses, o MLN estava militarmente derrotado. Em julho, os partidos tradicionais (inclusive com o apoio do setor de Ferreira Aldunate) garantiram a aprovação da Ley de Seguridad del Estado, ampliando as prerrogativas das medidas repressivas. Significativamente, a aprovação dessa lei permitiu que tudo aquilo que podia ser identificado como delito cometido contra o Estado passava para a jurisdição do Código Penal Militar como, por exemplo, atentados, serviços políticos ou militares, revelação de segredos, serviço de inteligência, sabotagens, etc (Art. $60^{\circ}$ ). A Ley de Seguridad del Estado conformava, portanto, o "marco legal" que legitimava a metodologia de ação das Forças Armadas e intensificava sua atuação "preventiva" e repressiva, como no caso corriqueiro das "batidas" nas residências da população.

A escalada do autoritarismo foi facilitada pelas divergências entre os setores democráticos no Parlamento diante dessa situação, como ocorreu quando da votação dessa lei, momento em que Wilson Ferreira Aldunate fundamentava seu apoio à mesma: "Vamos a votar cosas que no nos gustan. Pagamos este duro precio a cambio de seguridad" (ALFARO, s.d., p. 27). A implementação das medidas decorrentes da lei aprovada deteriorou, rapidamente, a relação entre os militares e o poder civil, levando o Parlamento a questionar os excessos institucionais das Forças Armadas.

Em outubro, aconteceu um primeiro ato de insubordinação das Forças Armadas diante da resolução de um juiz militar que mandara libertar quatro médicos presos. Os oficiais responsáveis pela sua detenção se negaram a cumprir a ordem, gerando um impasse que repercutiu em 
toda a cadeia de mando e culminou com a renúncia do Ministro da Defesa e na passagem à reserva do Comandante-em-Chefe do Exército. Quer dizer, mesmo quando ocasionalmente a Justiça Militar tomava alguma medida que discrepava do entendimento dos chefes militares, impunha-se o poder destes. Esse fato corroborou sintomas anteriores: o perigoso processo de autonomização e insubordinação das Forças Armadas diante dos poderes constituídos.

Entre março e setembro de 1972, os militares prenderam 1.441 pessoas acusadas de subversão; requereram outras 284; mataram 38 e feriram 19. No mesmo período, sofreram 18 mortos e 25 feridos. Em setembro, anunciavam a derrota do MLN. A violência da guerrilha deu ao governo legitimidade para convencer ou neutralizar, por apatia ou temor, setores importantes da sociedade que não questionaram os excessos cometidos na luta contra a subversão. Até para os partidos políticos foi se tornando muito difícil negar aos militares suas leis de exceção. A combinação de violência guerrilheira com manipulação da informação e explicitação de ação repressiva isolou os tupamaros. O medo diante de represálias físicas ou difamatórias ("traidores", "aliados da subversão") foi importante fator de paralisia e um dos grandes objetivos conseguidos pelo Terrorismo de Estado (ALFARO, s.d., p. 27).

\section{A ascensão militar ao poder}

O profissionalismo e o abstencionismo são características que marcaram as Forças Armadas uruguaias até os anos 1960, quando se intensificaram os cursos de formação para oficiais ditados pelo Pentágono, no marco da estratégia continental para os exércitos latinoamericanos, a qual impulsionava uma nova concepção das funções militares. Nelson Caula e Alberto Silva discordam da tese de que os soldados fossem despolitizados até o advento da ditadura (CAULA; SILVA, 1997, p. 63). Os autores retrocedem aos anos 1940 para registrar a presença de lojas militares onde certos setores conspiravam contra as instituições democráticas. Seu protagonismo, portanto, era perceptível desde antes dos anos 1960-70, bem como anterior ao surgimento das organizações guerrilheiras. Selva Lopez Chirico acrescenta que o marco para a análise da ação das Forças Armadas na conjuntura do Uruguai nos anos 1970 foi o processo de elaboração e de exportação da Doutrina de Segurança Nacional, por parte dos Estados Unidos, logo após o início da Guerra Fria. Mas considera que no Uruguai tal fato só teve impacto quando se aprofundou a crise resultante do esgotamento econômico e 
esta se combinou com a intensificação da mobilização popular e sindical, o surgimento da guerrilha urbana e a unificação política das esquerdas na Frente Ampla (LOPEZ CHIRICO, 1995).

Lopez Chirico esclarece ainda que a importação da Doutrina de Segurança Nacional ocorreu, num primeiro momento, sob intermediação brasileira e, posteriormente, a relação se estabeleceu diretamente com a própria matriz (estadunidense), mediante os fluxos do pan-americanismo e da Guerra Fria (LOPEZ CHIRICO, 1995).

A assimilação dos ensinamentos da luta contrainsurgente exigiu a maximização da estrutura de inteligência para a detecção do "inimigo interno", o que aproximou as tarefas militares das policiais, precedente que preparou o terreno para a posterior centralização de comando nas Fuerzas Conjuntas. Paralelamente, desenvolveram-se atividades que foram inseridas no marco da "ação cívica" visando a melhorar a imagem pública das Forças Armadas, dissociando-as do caráter mais repressivo e tornando-as mais presentes no envolvimento em atividades de infraestrutura física (construção de pontes, aeroportos, estradas, represas). Era a época em que as Forças Armadas ainda se regiam pelas diretrizes da Lei Orgânica Militar de 1941, que, no seu Art. 1º, dizia:

El Ejército Nacional tiene por misión esencial defender el honor, la independencia y la paz de la República, la integridad de su territorio, su Constitución y sus leyes, debiendo actuar siempre bajo el mando superior del Presidente de la República [...] (REPÚBLICA ORIENTAL DEL URUGUAY, 1941).

Essa lei foi substituída por uma nova Ley Orgánica Militar, em 1974, que, de acordo com os novos tempos, determinava:

Art. $1^{\circ}$ - Las Fuerzas Armadas son el nucleo básico de la población organizado para planificar y ejecutar los actos militares que impone la Defensa Nacional.

Art. $2^{\circ}-\mathrm{Su}$ misión fundamental consiste en dar la Seguridad Nacional exterior o interior (REPÚBLICA ORIENTAL DEL URUGUAY, 1974).

Um dado que reflete a evolução da ascensão do protagonismo militar na década de 1970 refere-se ao crescimento do número de efetivos vinculado ao emprego crescente da violência para enfrentar as tensões sociais do país. Os dados levantados por Lopez Chirico mostram que os 
setores vinculados à defesa da Segurança Nacional passaram de 42.235 (1970) para 49.235 (1973) e 64.303 (1978). Simultaneamente, criaram-se novas unidades, fruto da reestruturação modernizadora orientada pelos Estados Unidos.

Lopez Chirico também afirma que, entre 1970 e 1973, a ajuda militar anual do governo dos Estados Unidos havia aumentado de US\$1,9 milhão para US\$ 6 milhões e que a média de venda de material militar, entre 1970 e 1972, foi 17 vezes superior à média do período 19501969. Da mesma forma, registrou-se importante crescimento do fluxo de militares nas escolas de treinamento militar estadunidenses. Por outro lado, a fundação da Escuela Superior de Seguridad y Defensa Nacional (ESEDENA), em 1978, visou à conformação de uma elite civil-militar apta para administrar os assuntos de Estado e especializada em disciplinas relacionadas ao exercício do governo dentro dos marcos da "segurança para o desenvolvimento" (LOPEZ CHIRICO, 1995, p. 35).

Embora a presença da influência militar dos Estados Unidos no Uruguai seja anterior - assim como a participação de oficiais uruguaios nos diversos cursos ministrados pelo Exército estadunidense -, foi durante a gestão de Pacheco Areco que as Forças Armadas foram chamadas a cuidar de novas tarefas: a manutenção da ordem interna e a defesa do sistema econômico, social e político, iniciando um processo de sobreposição das funções militares e políticas das Forças Armadas e produzindo tensões entre o poder civil e o militar. Particularmente, em setembro de 1971, após a fuga massiva do presídio de Punta Carretas, os militares receberam, como já foi dito, a tarefa de elaborar e executar um Plano de Operações destinado a acabar com a subversão, o que lhes permitiu maior autonomia de ação para definir sua estratégia política, fortemente inspirada na Doutrina de Segurança Nacional (ALFARO, s.d., p. 25). A Resolução $n^{\circ} 1$ (secreta) do Plano de Operações da Junta de Comandantes en Jefe estabelecia como objetivo político: a) a luta militar contra a subversão, desmantelando a guerrilha urbana como passo imediato; b) a inserção das novas funções militares de seguridad nacional no sistema político e no ordenamento constitucional.

O atendimento da convocação de defender a Segurança Nacional produziu a ênfase repressiva contra o "inimigo interno", pautada na doutrina contrainsurgente, e também o fortalecimento dos setores "duros" no interior das Forças Armadas; ou seja, aqueles que assumiram a luta contrassubversiva (deslocando a papéis secundários os setores reconhecidos como "constitucionalistas") e que estavam 
mais influenciados pelas diretrizes que emanavam majoritariamente da Doutrina de Segurança Nacional, mas também pelas doutrinas repressivas da França (contra os revolucionários argelinos).

O fator repressão consolidou a fusão dos grupos "duros" com os governos Pacheco Areco e Bordaberry; a vitória militar contra o MLN significou, definitivamente, a perda de influência dos militares "constitucionalistas" dentro de cada uma das armas. Na prática, a maior parte deles acabou na reserva, por opção, pressão ou instrumentalização das regras de ascensão militar pelos setores vinculados organicamente ao governo. Alguns daqueles militares foram associados à "subversão" e acabaram presos; o caso mais emblemático foi o do general Líber Seregni e do grupo militar que o havia acompanhado na opção pela Frente Ampla. Portanto, a crise no interior das Forças Armadas se resolveu em favor dos setores mais alinhados à Doutrina de Segurança Nacional; seu resultado deixava como saldo da depuração interna " [...] un colectivo más cohesionado, homogéneo, autónomo y consustanciado con su función coercitiva" (LOPEZ CHIRICO, s.d., p. 25).

Em contrapartida, o fortalecimento do fator militar com a vitória sobre o MLN enfraqueceu, consideravelmente, o sistema político, percebido, cada vez mais, como uma estrutura inoperante, desarticulada e débil (NAHUM, 1995, p. 284). As Forças Armadas, desde sua irrupção no cenário político, procuraram discernir duas categorias de inimigos. Por um lado, os indivíduos associados com crimes de "subversão", ou seja, "[...] todos aquellos actos o situaciones, ajenos al derecho público al estilo de vida autóctono y a la básica escala de valores morales que deterioran el ordenamiento institucional, social, moral y económico nacional" (JUNTA DE COMANDANTES EN JEFE, 1978, p. 79). Por outro lado, aqueles indivíduos reconhecidos como sediciosos, especificidade subversiva constituída pelo conjunto de ações que "[...] pretende alterar el mencionado ordenamiento empleando medios violentos, o bien por la lucha armada" (JUNTA DE COMANDANTES EN JEFE, 1978, p. 80).

Isso significa reconhecer que as organizações armadas constituíram a "sedição" a ser enfrentada pelas Forças Armadas quando convocadas pelo presidente Pacheco Areco. Entretanto, a própria Doutrina de Segurança Nacional orientou para a flexibilização da figura do "inimigo interno" de forma a garantir a necessária permanência do novo protagonismo dos militares. Em outras palavras, a "sedição" foi compreendida como sendo a organização armada da "subversão". As forças de segurança uruguaias reconheceram que 
[...] ha existido en el país una sedición que ha sido contrarrestada por las FF.AA. en el terreno meramente militar, pero continúa existiendo una subversión, nadie puede negarlo, que afecta directamente la seguridad nacional. Así, pues, de acuerdo a la función y misión expresadas, las FF.AA están obligadas a empeñar hasta el último de sus esfuerzos para combatir y extirpar la subversión (JUNTA DE COMANDANTES EN JEFE, 1978, p. 80).

A ampliação do horizonte à procura de novos alvos "subversivos" é uma tentativa de convencimento da opinião pública já que, segundo os objetivos originários, a derrota da "sedição" (leia-se organizações armadas) significava a perda da legitimidade da permanência do protagonismo militar no plano político. Independente disso, após o golpe de Estado promovido por Bordaberry e seus associados militares, a fronteira entre a identificação entre "subversivo" ou "sedicioso" se diluiu e se confundiu, tornando-se, na prática, irrelevante.

O conceito subversão chega a ser tão amplo quanto ambíguo, como se constata numa reunião de suboficiais em agosto de 1972, onde os participantes

[...] manifiestan su profundo repudio a cualquier forma de subversión, ya sea la que empuña las armas para asesinar cobardemente, la que espolia la economía nacional, la que usurpa al pueblo el producto de su trabajo, la que lleva a la corrupción moral, administrativa y/o política, la que practica el agio y la especulación en desmedro de la población o la que compromete la soberanía nacional (LOPEZ CHIRICO, s.d., p. 26).

Uma questão cada vez mais delicada era a relação dos militares com o presidente Bordaberry. A persistência das Forças Armadas em ampliar sua autonomia, ultrapassando os limites constitucionais estabelecidos e frente à hesitação de Bordaberry em enquadrá-las, fez com que, no Parlamento, legisladores insatisfeitos pela permissividade do Poder Executivo começassem a levantar a hipótese de substituição do presidente. Dentro dessa conjuntura, uma nova sublevação do Exército ocorreu em fevereiro de 1973 produzindo a queda do general Francese, ministro da Defesa e homem de confiança de Bordaberry, de quem havia recebido a ordem de "frear os militares" (LOPEZ CHIRICO, s.d., p. 27). Nesse quadro, o Exército e a Força Aérea se insurgiram contra tal medida, enquanto a Marinha assumiu uma posição legalista ao lado de Bordaberry. Tal fato é digno de menção, pois foi a única vez em que 
houve divergência de tamanha relevância entre as distintas armas. Os líderes da insubordinação entraram em contato com a população através de um comunicado veiculado por cadeia nacional de rádio e televisão, onde "[...] han decidido desconocer las órdenes del Ministro de Defensa Nacional, Gral. Francese al mismo tiempo que sugerir al señor Presidente de la República la conveniencia de su relevo" (NAHUM, et al, 1994, p. 27).

Bordaberry, então, decidiu conclamar a cidadania a defender suas instituições. Concretamente, "“...] ni la población, ni el Parlamento, ni los partidos políticos acudieron al llamado de un Presidente por quien nadie se sintió representado" (ALFARO, s.d., p. 29). Até porque, “[...] el Presidente no tenia credibilidad alguna y era tan o más golpista que los sublevados (BRUSCHERA, 1986, p. 79). Bordaberry se submeteu à pressão; ao demitir seu ministro expôs a grave fragilidade do governo autoritário ane suas Forças Armadas.

Após esses acontecimentos, no mês de março, o Poder Executivo encaminhou à Assembleia Geral um projeto de "Consolidação da Paz" (lei do Estado peligroso) que aprofundava os traços repressivos. Tal pedido era justificado com a afirmação de que militarmente a subversão havia sido derrotada, mas que a organização ainda subsistia e podia ser reativada. A solicitação mostrou um visível contrassenso; se a subversão já estava militarmente derrotada - como reconhecia o governo -, para que se queriam mais prerrogativas legais para a ação repressiva? Aqui cabe retomar o alerta permanente exigido pela Doutrina de Segurança Nacional e a instrumentalização flexível do conceito de "inimigo interno". Não só se deviam eliminar os últimos resquícios do velho inimigo guerrilheiro, como deviam ser tomadas medidas preventivas para evitar o surgimento futuro de novos focos de contestação em outros espaços sociais (estabelecimentos de ensino, sindicatos, organizações de bairros), o que incluía "acompanhar" o comportamento dos políticos e dos partidos de oposição, assim como das organizações sociais, particularmente os estudantes e os trabalhadores.

O motivo que precipitou os eventos foi o pedido de cassação, feito pelo Poder Executivo, do senador frente-amplista Enrique Erro, acusado de estar envolvido com o MLN. A pressão do governo sobre o Parlamento se intensificou. Finalmente, a Câmara de Representantes, profundamente dividida, rejeitou a solicitação do governo (49 a 48 votos), fato que definiu o assalto final sobre a democracia. A atitude do Parlamento foi vista como provocação subversiva. Diante disso, 
[...] el 27 de junio, el Poder Ejecutivo decretó la disolución de las Cámaras y su substitución por un Consejo de Estado. Se disolvieron también las Juntas Departamentales, se estableció la censura de prensa y se limitó el derecho de reunión. La dictadura militar comenzaba su marcha (NAHUM, et al, 1994, p. 95).

\section{O desfecho do "Golpe em Câmera Lenta"}

No dia 27 de junho de 1973, unidades militares posicionaram-se estrategicamente em Montevidéu, assumiram o controle dos meios de comunicação e ocuparam o Palácio Legislativo. A seguir, o presidente Bordaberry comunicava à população a dissolução do Parlamento e a instalação de um Conselho de Estado. As autoridades departamentais (eleitas) foram substituídas (nenhuma pertencia à Frenta Ampla) e as empresas públicas foram intervindas. O ex-presidente Pacheco Areco, desde a Embaixada do Uruguai, na Espanha, aderiu ao golpe e anunciou o apoio da sua corrente política. Os demais setores colorados rejeitaram a ação e os blancos de Ferreira Aldunate procuraram articular-se, como resistência, com a Frente Ampla. O motivo pontual do golpe foi a recusa do Poder Legislativo ante o pedido de cassação, do senador Enrique Erro, feito pelo Poder Executivo. Acusado de ter ligações com o MLN, em realidade, Erro era visado por ser responsável pelas contundentes denúncias contra o governo e as Forças Armadas.

A Convenção Nacional de Trabalhadores (CNT) reagiu imediatamente e conclamou a greve geral; os locais de trabalho foram ocupados, bem como os prédios da Universidade e os liceos. Diante dessa reação, o governo decretou a dissolução da CNT e ordenou a detenção imediata dos seus dirigentes, acusando-os de subversão. A escalada de detenções, entre as quais as do presidente da Frente Ampla, Líber Seregni, obrigou, inclusive, a utilizar um estádio coberto (o Cilindro Municipal) como centro de reclusão.

Durante duas semanas, os trabalhadores enfrentaram o golpe de Estado com a greve geral. Porém, embora as significativas mobilizações e a tenaz resistência popular, a disparidade de forças se tornou um fator de desequilíbrio favorável aos setores golpistas. A direção da CNT, na clandestinidade, avaliou a dureza do enfrentamento, a tendência dos acontecimentos e o custo pago pelo movimento operário. Dividida entre a continuação da resistência a qualquer preço e o recuo tático para recompor forças e tentar retomar a luta, em uma conjuntura mais favorável, decidiu-se pela desmobilização. A verdade é que 
as possibilidades de retomar a luta, após a recomposição de forças, esfumaram-se rapidamente. A dinâmica repressiva desencadeada pelo governo impediu qualquer articulação. A CNT foi declarada ilegal, as greves foram proibidas e impôs-se uma nova legislação sindical que acabou com qualquer ilusão de retomada de ação ou autonomia do movimento sindical.

O encerramento da greve, por parte da CNT, inviabilizou a sobrevivência de uma resistência democrática e significou uma importante descompressão para o novo regime (NAHUM, 1995, p. 3). Neutralizada a CNT e a liderança da Frente Ampla, a ditadura continuou identificando novos alvos. Nesse sentido, rapidamente dissolveu partidos e organizações políticas de esquerda (PCU, PSU, 26 de Marzo, Unión Popular) e suspendeu as atividades políticas dos demais. Na área do Ensino, destituiu professores, fechou institutos de formação docente e interveio na Universidade após uma eleição cujo resultado contrariou os interesses do novo regime. Inúmeras organizações estudantis foram dissolvidas. O novo regime decidiu estender a identificação de inimigo a todo aquele que divergia do processo de reestruturação político e econômico que conduziam Bordaberry e as Forças Armadas.

Apesar da aparente obviedade, parece cabível reforçar que Juan María Bordaberry continuava utilizando o cargo de Presidente do Uruguai. Portanto, promoveu um autogolpe, ou seja, o presidente Bordaberry, eleito democraticamente, foi derrubado pelo ditador Bordaberry, mantido, rigorosamente, pelas Forças Armadas, enquanto eram fechadas as instituições democráticas e atropelavam-se as liberdades e o Estado de direito.

Em termos de perspectiva histórica o golpe dava início a uma ditadura que duraria até 1985. Para Milita Alfaro, suas origens devem ser procuradas

[...] en los desajustes estructurales que, presentes en nuestra realidad desde fines de la década del 50, conducirán a la crisis política que se hace irreversible en 1972. En esa coyuntura, la amenaza de la guerrilla desencadena la "ingobernabilidad" y el vacío de poder latentes desde tiempo atrás en el sistema, creando las condiciones para la inserción creciente de las FFAA en el aparato estatal, de acuerdo con las "nuevas funciones" que les asignaba la Doctrina de la Seguridad Nacional (ALFARO, s.d., p. 31).

Carlos Quijano, por sua vez, apontava a importância da administração Pacheco Areco no amadurecimento da espiral autoritária: "El 
señor Pacheco bien pronto (junio de 1968), a pretexto de combatir la subversión, implantó el estado de sitio que mantuvo, con algún breve intervalo, durante todo el período de su gobierno y continúa hasta hoy" (QUIJANO, 1989, p. 317). Para muitos setores, o golpe de Estado correspondeu ao amadurecimento de uma série de fatores que estavam marcando e tensionando a frágil democracia há alguns anos.

Por outro lado, se a presença cada vez mais decisiva das Forças Armadas estava vinculada ao golpe de Estado, então não há como dissociar o papel e o comportamento do MLN desse processo, já que sua ofensiva de abril de 1972 foi ao encontro das pretensões do governo de intensificar a repressão. Embora seja verdade que a organização estava militarmente derrotada antes do golpe (o que esvazia o argumento de que o mesmo foi necessário para enfrentar e derrotar a organização), é inegável que o fortalecimento dos militares e sua ascensão ao poder foram impulsionados pela necessidade de enfrentar, em certo momento, a guerrilha urbana. Ao longo de 1972, o desafio desta e a crise do sistema político criaram as condições para a ascensão das Forças Armadas ao poder.

É correto afirmar que os partidos políticos não participaram nem avalizaram o golpe (com exceção da corrente pachequista). Mas foram ineficientes para evitar que ele se confirmasse; blancos e colorados concederam aos militares funções que lhes escapavam reconhecendo prerrogativas que, mesmo temporárias, se confirmaram como permanentes (NAHUM, 1995, p. 283).

A insubordinação militar de fevereiro de 1973 tornara complexa a evolução do processo. A postura ambígua, confusa e dividida da esquerda e dos setores democráticos diante daquela situação tornou mais perceptível, para os setores golpistas das Forças Armadas, as enormes dificuldades dos políticos para orientarem-se de forma coerente em questões que deviam ser de consenso, como a defesa da democracia, da Constituição e da figura do Presidente da República.

Bordaberry constata a postura diferente de setores da sociedade civil e política nos eventos de fevereiro e de junho de 1973, mas poderia ampliar seu horizonte de reflexão e contribuir para o debate se também fizesse sua autocrítica no sentido de tentar entender e explicar por que a sociedade uruguaia tinha tanta dificuldade em identificá-lo ou associá-lo à democracia, à Constituição e à própria Presidência da República.

Para concluir, tecem-se as seguintes considerações. É inegável que houve uma linha de continuidade entre os governos "constitucionais" 
de Pacheco Areco e de Bordaberry quanto a uma escalada autoritária gerada desde 1968. Não é pertinente considerar que os governos desse período tenham sido iguais, na sua essência, ao regime ditatorial que se instalou em junho de 1973. Mas o estudo do período imediatamente anterior ao golpe de Estado aponta, a partir da consulta documental e dos depoimentos dos protagonistas, a existência de diversas conexões que permitem estabelecer algumas afirmações finais.

Em primeiro lugar, considerando a noção de processo histórico, houve evidente deterioração das relações políticas, marcada por diversos solavancos (execução de Dan Mitrione pelos tupamaros, eleições de 1971, "14 de abril” de 1972, insubordinação militar, etc). Tais relações funcionaram como pontos de inflexão resultantes da combinação de crise estrutural com conjuntura internacional que, de forma explosiva, se projetava e se manifestava no continente.

Em segundo lugar, a ditadura civil-militar se configurou, definitivamente, em junho de 1973, mas é inegável que, como ameaça potencial, foi se gestando desde 1968. O que significa inferir também que a democracia realmente existente no Uruguai, na segunda metade dos anos 1960, estava muito distante da aludida "Suíça da América" ou de uma propalada democracia forte e estável, muitas vezes apontada como cenário destruído pelo regime de Segurança Nacional. Isto não significa desconhecer que, mesmo assim, tratava-se de uma democracia (mesmo que frágil), nem que não existisse uma crença na tradição democrática da dinâmica política do país.

Em terceiro lugar, o Terrorismo de Estado foi a essência da ditadura de Segurança Nacional uruguaia. Como tal, constituiu-se a partir do momento em que as Forças Armadas tiveram condições de ordenar a sociedade de forma plena, segundo seus objetivos e critérios. Isto começou a ocorrer não só em junho de 1973, mas a partir da claudicação do poder civil e, particularmente, do governo Bordaberry, em fevereiro de 1973.

\section{Referências}

ALFARO, Milita. El derrumbe de la Suiza de América. El Pachequismo y el Golpe Militar. Montevideo: Las Bases, s.d. 34 p.

BUCHELI, Gabriel. Los inicios: rastreando los orígenes de la violencia política en el Uruguay de los 60. Cuadernos de la historia reciente: Uruguay (1968-1985). Montevideo: Banda Oriental, v. 4, p. 67-83, 2008.

BRUSCHERA, Oscar H. Las décadas infames. Análisis político 1967-1985. Montevideo: Lunardi y Risso, 1986. 189 p. 
CAULA, Nelson; SILVA, Alberto. Alto el fuego. La Logia de los Tenientes de Hitler. Montevideo: Rosebud, 1997. v. 2. 292 p.

DEMASI, Carlos. La evolución del campo político en la dictadura. In: DEMASI, Carlos et al. La dictadura Cívico-Militar: Uruguay (1973-1985). Montevideo: Banda Oriental, 2009. p. 15-109.

FERNANDES, Ananda Simões. Quando o inimigo ultrapassa a fronteira: as conexões repressivas entre a ditadura civil-militar brasileira e o Uruguai (1964-1973). 2009. 274 f. Porto Alegre. Dissertação. Programa de Pós-Graduação em História - Universidade Federal do Rio Grande do Sul.

JELLINECK, Sergio; LEDESMA, Luis. Uruguay: del consenso democrático a la militarización estatal. Estocolmo: Institute of Latin American Studies, 1980. 90 p.

JUNTA DE COMANDANTES EN JEFE. Las Fuerzas Armadas al pueblo oriental: el proceso político. Montevideo, 1978. t. 2. 746 p.

LOPEZ CHIRICO, Selva. Las Fuerzas Armadas. De la milicia artiguista al Ejército de Seguridad Nacional. Montevideo: Las Bases, s.d. 34 p.

LOPEZ CHIRICO, Selva. Uruguai 1985-1993. Estratégia e tática da reprodução institucional militar no pós-ditadura. 1995. 346 f. Campinas/SP. Tese. Programa de Pós-Graduação em Ciências Sociais - Universidade de Campinas.

MARTÍNEZ, Virginia. Los fusilados de abril. ¿Quién mató a los comunistas de la 20 ? Montevideo: Caballo Perdido, 2002. 142 p.

MLN-TUPAMAROS. Aviso a la población. 14/04/1972.

NAHUM, Benjamin; et al. El fin del Uruguay liberal 1959-1973. Montevideo: Banda Oriental, 1994. t. 8. 184 p.

NAHUM, Benjamín. Manual de Historia del Uruguay 1903-1990. Montevideo: Banda Oriental, 1995. 383 p.

PADRÓS, Enrique Serra. Como el Uruguay no hay... Terror de Estado e Segurança Nacional. Uruguai (1968-1985): do Pachecato à ditadura civil-militar. 2005. 875f. Porto Alegre. Tese. Programa de Pós-Graduação em História - Universidade Federal do Rio Grande do Sul.

PADRÓS, Enrique Serra; FERNANDES, Ananda Simões. O 68 no Uruguai: crise estrutural, mobilização social e autoritarismo. História: debates e tendências. Passo Fundo/RS: UPF, v. 8, n. 1, p. 28-49, jan./jul. 2008.

QUIJANO, Carlos. Los golpes de Estado (1973). Montevideo: Cámara de Representantes, 1989. v. 2. 389 p.

REPÚBLICA ORIENTAL DEL URUGUAY. Registro Nacional de Leyes y Decretos. Ley n ${ }^{\circ}$ 10.050, Ley Orgánica Militar. 27/09/1941.

REPÚBLICA ORIENTAL DEL URUGUAY. Registro Nacional de Leyes y Decretos. Ley $n^{\circ}$ 14.068, Ley de Seguridad del Estado y el Orden Interno. 10/07/1972.

REPÚBLICA ORIENTAL DEL URUGUAY. Registro Nacional de Leyes y Decretos. Ley n ${ }^{\circ}$ 14.157, Ley Orgánica Militar. 05/03/1974.

VARELA, Gonzalo. De la República Liberal al Estado Militar. Crisis politica en Uruguay (1968-1973). Montevideo: Nuevo Mundo, 1988. 204 p. 